\title{
GLII genotypes do not predict basal cell carcinoma risk: a case control study
}

\author{
Andrea Watson 1 , Paul Kent ${ }^{2}$, Murad Alam³ ${ }^{3}$ Amy S Paller ${ }^{3}$, \\ David M Umbach ${ }^{4}$, Joon Won Yoon ${ }^{5}$, Philip M Iannaccone ${ }^{5}$ and \\ David O Walterhouse*5
}

\begin{abstract}
Address: ${ }^{1}$ Department of Pediatrics, University of Minnesota - Duluth, Minnesota, USA, ${ }^{2}$ Department of Pediatrics, Rush University Medical Center, Chicago, Illinois, USA, ${ }^{3}$ Department of Dermatology, Northwestern University Feinberg School of Medicine, Chicago, Illinois, USA, ${ }^{4}$ Biostatistics Branch, National Institute of Environmental Health Sciences, National Institutes of Health, Research Triangle Park, North Carolina, USA and ${ }^{5}$ Department of Pediatrics, Northwestern University, Feinberg School of Medicine and the Developmental Biology Program of the Children's Memorial Research Center, Chicago Illinois, USA

Email: Andrea Watson - Awatson1@smdc.org; Paul Kent - P_Kent@rush.edu; Murad Alam - m-alam@northwestern.edu; Amy S Paller - Apaller@nmff.org; David M Umbach - umbach@niehs.nih.gov; Joon Won Yoon - j-yoon2@northwestern.edu; Philip M Iannaccone - pmi@northwestern.edu; David O Walterhouse* - d-walterhouse@northwestern.edu

* Corresponding author
\end{abstract}

This article is available from: http://www.molecular-cancer.com/content/8/I/II3

(c) 2009 Watson et al; licensee BioMed Central Ltd.

This is an Open Access article distributed under the terms of the Creative Commons Attribution License (http://creativecommons.org/licenses/by/2.0), which permits unrestricted use, distribution, and reproduction in any medium, provided the original work is properly cited.

\begin{abstract}
Background: Susceptibility to basal cell carcinoma results from complex interactions between ultraviolet radiation exposure and genetic factors. The GLII oncogene is believed to play a role in the genesis of these tumors. We determined whether GLII polymorphisms were risk factors for developing basal cell carcinoma, either alone or in combination with patterns of past sun exposure, and whether there were functional differences among different GLII haplotypes.

Results: GLII genotypes at c.2798 and c.3298 from 20 I basal cell carcinoma patients were compared to $20 \mathrm{I}$ age and sex-matched controls. Neither genotype nor haplotype frequencies differed between cases and controls. However, the odds of developing basal cell carcinoma on the trunk compared to the head/neck appeared somewhat lower with carriers of the c.3298GC than the CC genotype. There was no evidence for interactions between skin type, childhood sunburning, average adult sun exposure, adult sunbathing, or intermittency of sun exposure and GLII haplotype. Additionally, we found no significant differences in transcription activation or cell transforming ability among the four GLII haplotypes.
\end{abstract}

Conclusion: These results suggest that different GLI/ genotypes alone or in combination with past sun exposure patterns as assessed in this study do not affect basal cell carcinoma risk.

\section{Background}

Basal cell carcinoma (BCC) is the most common malignancy in Caucasians. Although mortality associated with BCC is low, BCC accounts for significant morbidity and places a large burden on the health care system. Suscepti- bility to BCC is believed to result from complex interactions between environmental ultraviolet (UV) radiation exposure and genetic factors [1]. Polymorphisms in genes encoding detoxifying enzymes (cytochrome p450 and glutathione S-transferase), the melanocortin 1 receptor, 
Agouti signaling protein, tyrosinase, and Patched 1 (PTCH1) have been associated with BCC risk [2-5]. However, polymorphic loci in genes that determine susceptibility for many patients who develop BCC and account for the phenotypic variability of BCC remain to be identified.

Dysregulation of the Sonic hedgehog signal transduction pathway plays an important role in the pathogenesis of BCC, presumably based on constitutive activation of GLI family transcription factors [6-8]. Indeed, transgenic mice expressing GLI1 in cutaneous keratinocytes develop BCCs, providing evidence that GLI1 plays a role in the genesis of BCC [9].

Polymorphic loci of unknown functional significance have been identified in GLI1, including c.2651A>C (D884A), c.2798G>A (G933D), c.3034G>T (G1012V), and c.3298G>C (E1100Q) [10,11]. None of these loci lies in a known functional domain of GLI1, however, nucleotides c. 2798 , c.3034, and c.3298 flank the carboxy terminal acidic transactivation domain (c.3060 - c.3273) [12]. Theoretically, amino acid differences in these residues could affect the conformation or function of this domain and be associated with disease based on altered transcriptional regulation by GLI1. Since GLI1 expression appears to play a fundamental role in the genesis of BCC, we determined whether any of the GLI1 genotypes represent risk factors for developing BCC alone or in combination with past sun exposure patterns and whether functional differences exist among the haplotypes. We find that different GLI1 genotypes alone or in combination with past sun exposure patterns as assessed in this study do not affect BCC risk.

\section{Methods \\ Study design and subjects}

A frequency-matched case control study was conducted from February to November 2007. Controls were matched to cases on sex and age (20-39 years, 40-59, 60$69, \geq 70$ ). In an attempt to even the distribution among age categories, we chose broader intervals where we expected fewer cases and narrower ones where we expected more.

In accord with the Declaration of Helsinki protocols, institutional IRB approval was granted from the Northwestern University Feinberg School of Medicine and Children's Memorial Hospital prior to study initiation. Written informed consent was obtained from each subject prior to enrollment. Eligible cases were recruited from non-Hispanic Caucasian patients presenting to the Northwestern Memorial Faculty Foundation Dermatology clinic for Mohs resection of histologically confirmed non-metastatic BCC. Eligible controls that had no history of skin cancer were also recruited from non-Hispanic Caucasian patients presenting to the same clinic. Individuals who had a known genetic disease or syndrome were excluded. Information collected included age, sex, skin type, and BCC location. Fitzpatrick skin type was ascertained by the patient's response to a standardized question [13]. BCC location was recorded as head/neck, trunk, or extremity.

\section{Single Nucleotide Polymorphism (SNP) analysis}

Two buccal swabs (Whatman Omniswab, Florham Park, NJ) were obtained from consenting cases and controls. Genomic DNA was extracted using the QIAmp DNA mini kit (Qiagen, Valencia, CA). Two SNPs in the GLI1 gene (c.2798G >A and c.3298G>C) were analyzed via matrixassisted laser desorption ionization time-of-flight mass spectrometry (MALDI-TOF MS) by the Translational Genomics Research Institute (TGen, Phoenix, AZ). The c.2651A>C (D884A) SNP was not analyzed based on its rare occurrence. The c.3034G>T (G1012V) SNP was not analyzed because it has only been observed in the Asian population [11].

\section{Assessment of sun exposure}

A validated sun exposure questionnaire was completed by cases $(\mathrm{N}=201)$ and controls $(\mathrm{N}=201)$ in clinic [14-17]. Estimates for each of four aspects of sun exposure were determined (1. average adult sun exposure, 2. adult sunbathing score, 3 . childhood sunburning, and 4. intermittency score). A measure of the lifetime average sun exposure in hours/day beginning at age 20 years is referred to as the average adult sun exposure. Within each age range a weighted average number of hours of exposure per day was calculated. These averages were combined across the age ranges as a weighted average with weights proportional to the number of years the subject spent in each age range. The adult sunbathing score serves as a measure of time that is spent with a large area of the body exposed to the sun. Nominal categories were converted to a numerical score for each age range as never $=0$, rarely $=$ 1 , occasionally $=2$, and often $=3$. A weighted average of a subject's age-range-specific scores was calculated based on the number of years spent in each age range. Childhood sunburning was defined as erythema for $\geq 48$ hours or blistering and recorded as yes or no. The intermittency score provides a measure of the proportion of sun exposure received on non-working days. Intermittency was assessed based on the absolute value of the difference between the weekend and weekday hours of exposure for a subject. An absolute value was determined for each of the age ranges in which a subject had spent time, and the values were combined across the age ranges as a weighted value based on the number of years the subject spent in each age range. 


\section{Functional analysis}

For CAT assays, GLI1 cDNA expression constructs that included nucleotides 231 through the polyA tail were prepared in the pM plasmid (Clontech, Palo Alto, CA) for each of four haplotypes (c.2798G>A and c.3298G>C). The sequence of all constructs was confirmed by automated sequence analysis. A total of $4 \mu \mathrm{g}$ of DNA was transfected into HeLa cells in each experiment using Lipofectamine reagent (Gibco-BRL, Rockville, MD), including $1 \mu \mathrm{g}$ of pG5CAT reporter plasmid (Clontech, Palo Alto, CA), $1 \mu \mathrm{g}$ of pSV- $\beta$-galactosidase (Promega, Madison, WI), 0-250 ng of GLI1 effector plasmid, and pBluescript carrier DNA (Stratagene, La Jolla, CA) in an amount to make up the difference. CAT assays were performed as described by the manufacturer (Clontech, Palo Alto, CA). CAT activity was quantitated by scintillation counter and was normalized by measuring $\beta$-galactosidase activity spectrophotometrically.

For transformation assays, pLTR-GLI1 expression constructs containing each of the haplotypes in the pLTR-2 vector were prepared [18]. The sequence of all constructs was confirmed by automated sequence analysis. RK3E cells (American Type Culture Collection CRL1895, Manassas, VA) were transfected with $3 \mu \mathrm{g}$ of each of the pLTRGLI1 constructs using $12 \mu \mathrm{l}$ of Lipofectamine reagent in $0.3 \mathrm{ml}$ of OptiMEM (Gibco-BRL, Rockville, MD) [18]. Cells were incubated for $5 \mathrm{hr}$ at $37^{\circ} \mathrm{C}$ before the OptiMEM was replaced with fresh culture media. Cells were incubated for two to four weeks and foci were counted.

\section{Statistical analysis}

Hardy-Weinberg Equilibrium at each locus and estimates of linkage disequilibrium between loci were assessed using standard methods [19]. We assessed associations between BCC and potential risk factors (e.g., genotypes or sun exposure variables) using unconditional logistic regression models that adjusted for the matching variables. Interactions between potential risk factors were assessed similarly. We assessed associations between BCC location and genotype or exposure variables using unconditional polytomous logistic regression models applied only to cases. These models regarded the three possible locations as outcomes and the other variables as predictors. These polytomous models were also adjusted for the matching variables. Both the case-control logistic regression and case-only polytomous logistic regression measured associations with odds ratios (OR), and provided corresponding confidence intervals (CI) and two-tailed statistical tests. All regression calculations were carried out with SAS version 9.1 statistical software (SAS Institute, Inc., Cary, NC).

Analyses of possible associations of sun exposure variables or genotype with skin type were always adjusted for case-control status. Association of childhood sunburning with skin type was assessed with the Cochran-Armitage trend test. Associations of continuous sun exposure variables with skin type were assessed using tests for linear trend embedded in an analysis-of-variance model. Associations of GLI1 genotypes with skin type were assessed with the Cochran-Mantel-Haenszel test. These calculations were carried out with either SAS version 9.1 or with StatXact 6 (Cytel Software Corporation, Cambridge, MA).

\section{Results}

\section{Characteristics of cases and controls}

419 of 443 subjects (95\%) interviewed met eligibility criteria, and 402 of 419 eligible individuals (96\%) were enrolled. Buccal swabs, assessment of Fitzpatrick skin type, and sun-exposure questionnaires were obtained from 201 cases and 201 controls. Controls were frequency-matched to cases for age and sex (Table 1). The slight matching imbalances arose from an excess of female controls in the 40-59 age class and an excess of cases of both sexes in the $\geq 70$ age class. The location of the BCC was head/neck in 157 (78\%), trunk in $25(12 \%)$, and extremity in 19 (10\%). With the limited data available, we saw no evidence that the site distribution was related to either age or to sex.

\section{GLII genotype and haplotype frequencies among cases and controls}

GLI1 genotype distributions for nucleotides c. 2798 and c.3298 for both the cases and controls were consistent with Hardy-Weinberg Equilibrium (cases: c. $2798 \mathrm{p}=0.4$, c.3298 p = 0.8; controls: c.2798 p =0.06, c.3298 p = 0.2). The genotype frequencies were not significantly different between the cases and controls at c. 2798 or c. 3298 whether adjusted for age and sex or not (Additional file 1). Estimated haplotype frequencies were also not significantly different. Since we found no evidence for an association between haplotype and BCC, we combined cases and controls to estimate haplotype frequencies for the

Table I: Matching of Cases and Controls for Age and Sex

\begin{tabular}{|c|c|c|c|c|}
\hline & \multirow{2}{*}{$\begin{array}{c}\text { Cases } \\
\mathbf{N}\end{array}$} & \multicolumn{3}{|c|}{ Controls } \\
\hline & & $\%$ & $\mathbf{N}$ & $\%$ \\
\hline Total & 201 & 100 & 201 & 100 \\
\hline \multicolumn{5}{|c|}{ Age (years) } \\
\hline 20-39 & 14 & 7 & 10 & 5 \\
\hline $40-59$ & 55 & 27 & 65 & 32 \\
\hline $60-69$ & 56 & 28 & 58 & 29 \\
\hline$\geq 70$ & 76 & 38 & 68 & 34 \\
\hline \multicolumn{5}{|l|}{ Sex } \\
\hline female & 91 & 45 & 96 & 48 \\
\hline male & 110 & 55 & 105 & 52 \\
\hline
\end{tabular}


population; с.2798A;c.3298C $=0.58$, c. $2798 \mathrm{~A} ; \mathrm{c} .3298 \mathrm{G}=$ 0.001, c. $2798 \mathrm{G} ; \mathrm{c} .3298 \mathrm{C}=0.08$, and c. $2798 \mathrm{G} ; \mathrm{c} .3298 \mathrm{G}=$ 0.34 .

To estimate variability in GLI1 genotype distributions among different control groups, we compared the c.2798 and c.3298 genotype frequencies in our controls with a published historic control group consisting of a healthy Australian population with no evidence of BCC or other cancers [10]. We did not find evidence for any differences in the genotype distribution between our controls and the historic controls at c.2798 ( $\mathrm{p}=0.6)$. However, we found that the genotype distribution at c.3298 differed between the two groups $(\mathrm{p}=0.006)$.

It has been suggested that different mechanisms mediate the development of truncal BCC compared with BCC on other sites. Therefore, we looked for associations between GLI1 genotype with primary site. We found no evidence for an association between the c. 2798 genotype and BCC location (Additional file 2). However, the odds of developing BCC on the trunk compared with the head/neck region was lower for carriers of the $\mathrm{GC}$ than the $\mathrm{CC}$ genotype at c.3298. The power of this association is limited by the small number of truncal cases.

\section{Skin type and sun exposure estimates for cases and controls}

Skin type distribution ( $\mathrm{N}=402$ ) was not significantly different among cases and controls, whether adjusted for age and sex or not (Additional file 3). Although OR estimates point in the direction of a slight protective effect against developing BCC for individuals with skin types III + IV compared to I + II, we do not have evidence that skin type is associated with BCC ( $\mathrm{p}=0.32$ when adjusted for age and sex). Skin type was not associated with BCC location (Additional file 4), and we did not find evidence for interactions between skin type and GLI1 genotype that affect BCC risk (Additional file 5).

There was not an association between any of the sunexposure variables and BCC or between the adult sunbathing score or childhood sunburning and BCC location whether adjusted for age and sex or not (Additional files $3,4)$. Longer average adult sun exposure appeared to reduce the odds of $\mathrm{BCC}$ developing on the trunk compared to the head/neck ( $\mathrm{p}=0.05)$ (Additional file 4), while intermittency appeared to be associated with BCC site $(\mathrm{p}=0.04)$ and with increased odds of developing BCC on the extremities compared to the head/neck ( $\mathrm{p}=0.02)$ (Additional file 4). There was not evidence for interactions between patterns of past sun exposure and either GLI1 genotype or haplotype (data not shown).

\section{Functional analyses of the different GLII haplotypes}

We tested the ability of each of the GLI1 haplotypes to activate transcription and transform RK3E cells in culture. We found no significant differences in activity among the four haplotypes by either of these assays (Figure 1). Introduction of point mutations that change a specific residue in the acidic transactivation domain of GLI1 significantly reduced GLI1-induced transactivation of the pG5CAT reporter (c.3345 T>G and c.3346 T>C [F1048A]), demonstrating that the assay is sensitive enough to detect functional differences caused by single amino acid changes. These results support the conclusion that different GLI1 haplotypes function similarly.

\section{Discussion}

We did not find evidence that different GLI1 genotypes alone or in combination with past sun exposure patterns affect BCC risk. Additionally, we found no significant differences in transcription activation or cell transforming ability among the four GLI1 haplotypes.

The genotype distribution of our controls differed from a historic control group at c.3298. It is unclear whether the differences represent variation within the US Midwest population or inherent differences in the genetic distribution between distinct populations world-wide. In either case, it will be important to carefully select internal controls for future studies that assess GLI1 genotype frequencies.

It is not entirely surprising that skin type distribution and sun exposure estimates did not differ between our cases and controls since associations between these and BCC have been inconsistently reported $[14,16,17]$. We recognize that recall bias may limit the validity of the sun-exposure estimates and reduce their value in determining associations between BCC and specific past sun exposure patterns. Similar to other studies, participants self-administered the questionnaire in clinic to reduce the introduction of bias. In contrast to the other studies, we compared BCC patients to individuals who were generally well and without BCC. It is not clear why this comparison would give negative results. It is also possible that perceptions of sunbathing practices or genetic heterogeneity differ between individuals in different populations, sometimes limiting the discriminating value of the questionnaire. Finally, it is possible that UV radiation played a limited role in the development of BCC in the population that was assessed.

\section{Conclusion}

GLI1 genotypes function similarly and do not affect BCC risk either alone or in combination with past sun exposure patterns. 
A

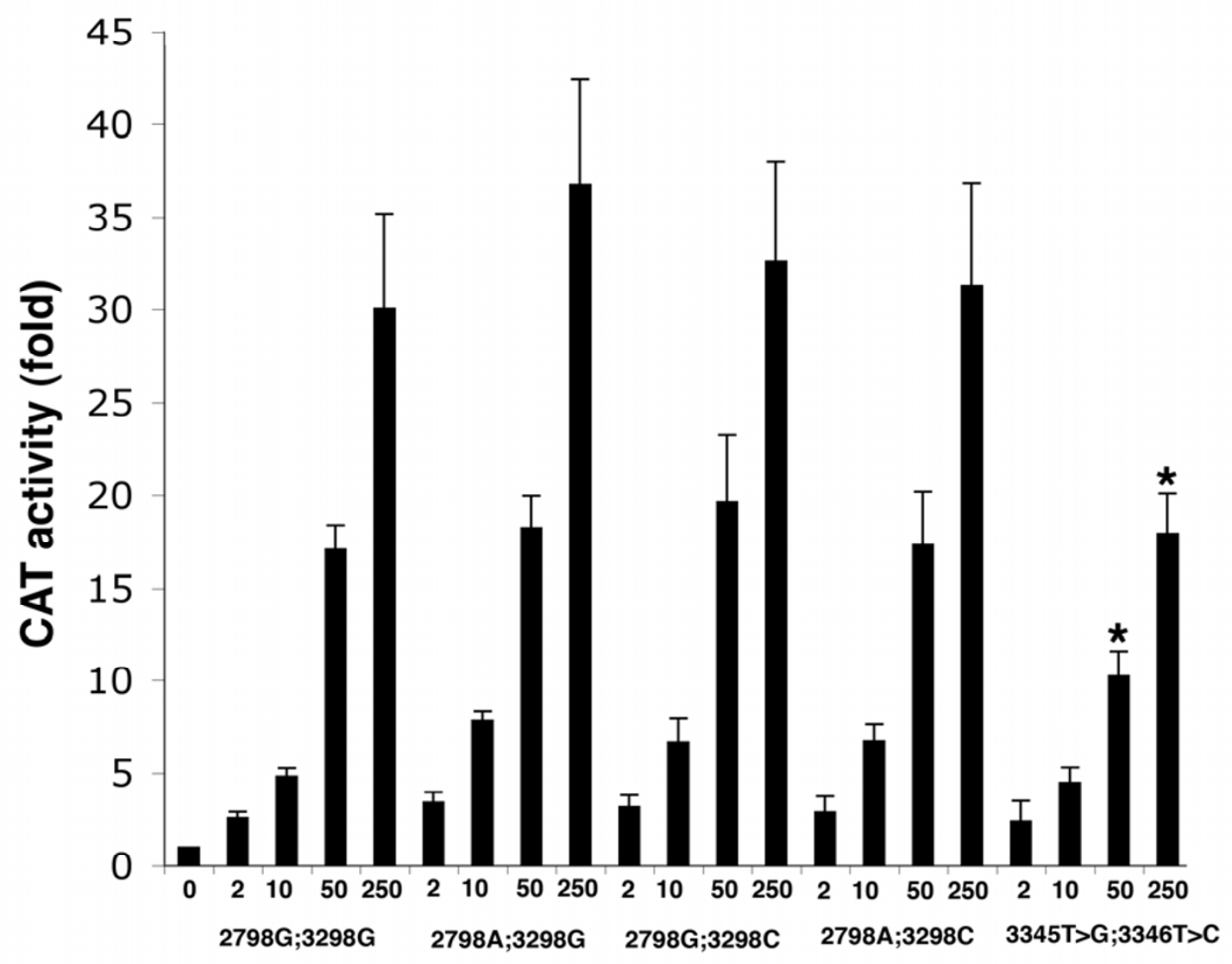

B

\begin{tabular}{llcl}
\hline Expression construct & Number of foci per 60mm dish & Mean +/- SD & $P$ value \\
\hline None & $0,0,0$ & 0 & --- \\
Antisense GLII & $0,0,0$ & 0 & --- \\
$2798^{\mathrm{G}} 3298^{\mathrm{G}}$ & $24,27,25$ & $25.33 \pm 1.53$ & --- \\
$2798^{\mathrm{G}} 3298^{\mathrm{C}}$ & $31,25,20$ & $25.33 \pm 5.51$ & 1.00 \\
$2798^{\mathrm{A}} 3298^{\mathrm{G}}$ & $30,31,27,33,19,22$ & $27.00 \pm 5.48$ & 0.50 \\
$2798^{\mathrm{A}} 3298^{\mathrm{C}}$ & $25,32,28$ & $28.33 \pm 3.51$ & 0.25 \\
\hline
\end{tabular}

\section{Figure I}

Different GLII haplotypes function similarly. A. Different GLII haplotypes activate transcription of a CAT reporter comparably in HeLa cells. The GLII haplotypes are indicated along the abscissa with the amount transfected (ng) in each experiment. CAT activity, normalized by measuring $\beta$-galactosidase activity spectrophotometrically (Promega, Madison, $\mathrm{WI}$ ), is indicated on the ordinate. Bars represent the means derived from three independent experiments. *indicates $p<0.05$ calculated using a test of difference between means, comparing 2798G;3298G with the corresponding amount of each of the other haplotypes. B. Different GLII haplotypes transform RK3E cells comparably. The p value represents a test of difference between means, comparing 2798G;3298G with each of the other GLII haplotypes. 


\section{Competing interests}

The authors declare that they have no competing interests.

\section{Authors' contributions}

AW collected patient data, participated in data analysis, and drafted the manuscript. PK collected patient data. MA participated in patient data collection, study design, and manuscript revision. AP participated in study design, and manuscript revision. DU contributed to study design, completed data analysis, participated in data interpretation, and helped to draft and revise the manuscript. JY carried out the transcription and transformation assays, and participated in manuscript revision. PI participated in study design, data analysis, data interpretation, and manuscript revision. DW conceived of the study, participated in study design, data analysis, data interpretation, and manuscript revision. All authors read and approved the final manuscript.

\section{Authors' Information}

AW, PK, and DW are pediatric oncologists. AP is a dermatologist. MA is a dermatologist and cutaneous surgeon. JY is a developmental biologist. PI is a pathologist and developmental biologist. DU is a statistician.

\section{Additional material}

\section{Additional file 1}

Association of GLI1 genotypes with BCC.

Click here for file

[http://www.biomedcentral.com/content/supplementary/1476-

4598-8-113-S1.DOC]

\section{Additional file 2}

Association of GLI1 genotypes with BCC site.

Click here for file

[http://www.biomedcentral.com/content/supplementary/1476-

4598-8-113-S2.DOC]

\section{Additional file 3}

Association of sun-exposure variables with BCC.

Click here for file

[http://www.biomedcentral.com/content/supplementary/14764598-8-113-S3.DOC]

\section{Additional file 4}

Association of sun exposure variables with BCC site (adjusted for age and sex).

Click here for file

[http://www.biomedcentral.com/content/supplementary/14764598-8-113-S4.DOC]

\section{Additional file 5}

Association of BCC with cross-classification of GLI1 genotypes and dichotomized skin type.

Click here for file

[http://www.biomedcentral.com/content/supplementary/14764598-8-113-S5.DOC]

\section{Acknowledgements}

This work was supported in part by the Washington Square Foundation, the Illinois Department of Public Aid ("Excellence in Academic Medicine" Award), the Illinois Regenerative Medicine Institute Initiative, the George M. Eisenberg Foundation for Charities, and the Intramural Research Program of the NIH, National Institute of Environmental Health Sciences.

\section{References}

I. Armstrong BK, Kricker A: The epidemiology of UV induced skin cancer. JPhotochem Photobiol B 200I, 63:8-18.

2. Lear JT, Smith AG, Bowers B, Heagearty AH, Jones PW, Gilford J, Alldersea J, Strange RC, Fryer AA: Truncal tumor site is associated with high risk of multiple basal cell carcinoma and is influenced by glutathione S-transferase, GSTTI, and cytochrome P459, CYPIAI genotypes, and their interaction. J Invest Dermatol 1997, 108:519-522.

3. Liboutet M, Portela M, Delestaing G, Vilmer C, Dupin N, Gorin I, Saiag P, Lebbe C, Kerob D, Dubertret L, Grandchamp B, BassetSequin N, Soufir N: MCIR and PTCH gene polymorphism in French patients with basal cell carcinomas. I Invest Dermatol 2006, 126:1510-1517.

4. Gudbjartsson DF, Sulem P, Stacey SN, Goldstein AM, Rafnar TH, Sigurgeirsson B, Benediktsdottir KR, Thorisdottir K, Ragnarsson R, Sveinsdottir SG, Magnusson V, Lindblom A, Kostulas K, BotellaEstrada R, Soriano V, Juberias P, Grasa M, Saez B, Andres R, Scherer D, Rudnai P, Gurzau E, Koppova K, Kiemeney LA, Jakobsdottir M, Steinberg S, Helgason A, Gretarsdottir S, Tucker MA, Mayordomo Jl, Nagore E, Kumar R, Hansson J, Olafsson JH, Gulcher J, Kong A, Thorsteinsdottir U, Stefansson K: ASIP and TYR pigmentation variants associate with cutaneous melanoma and basal cell carcinoma. Nat Genet 2008, 70:886-891.

5. Scherer D, Bermejo JL, Rudnai P, Gurzau E, Koppova K, Hemminki K, Kumar R: MC IR variants associated susceptibility to basal cell carcinoma of skin: Interaction with host factors and XRCC3 polymorphism. Int J Cancer 2008, I 22: I787-1793.

6. Gailani MR, Stahle-Backdahl M, Lefell DJ, Glynn M, Zaphiropoulos PG, Pressman C, Unden AB, Dean M, Brash DE, Bale AE, Toftgard R: The role of the human homologue of Drosophila patched in sporadic basal cell carcinomas. Nat Genet 1996, 14:78-8I.

7. Xie J, Murone M, Luoh SM, Ryan A, Gu Q, Zhang C, Bonifas JM, Lam CW, Hynes M, Goddard A, Rosenthal A, Epstein EH Jr, de Sauvage FJ: Activating Smoothened mutations in sporadic basal-cell carcinoma. Nature 1998, 391:90-92

8. Dahmane N, Lee J, Robbins P, Heller P, Ruiz i Altaba A: Activation of the transcription factor Gli I and the Sonic hedgehog signalling pathway in skin tumours. Nature 1997, 389:876-88I.

9. Nilsson $M$, Unden AB, Krause D, Malmqwist U, Raza K, Zaphiropoulos PG, Toftgard R: Induction of basal cell carcinomas and trichoepitheliomas in mice overexpressing GLI-I. Proc Natl Acad Sci USA 2000, 97:3438-3443.

10. Wang XQ, Chan N, Rothnagel JA: Letters to the editor: identification of polymorphic variants of the GLII oncogene. J Invest Dermatol 2000, I 1 5:328-329.

II. Qiu GR, Gong LG, He G, Xu XY, Xin N, Sun GF, Yuan YH, Sun KL: Association of the GLI gene with ventricular septal defect after the susceptibility gene being narrowed to $3.56 \mathrm{cM}$ in I 2q 13. Chin Med J 2006, I 9:267-274.

12. Yoon JW, Liu CZ, Yang JT, Swart R, lannaccone P, Walterhouse D: GLI Activates Transcription through a herpes Simplex Viral Protein 16-Like Activation Domain. J Biol Chem 1998, 273:3496-350I 
13. Fitzpatrick TB: The validity and practicality of sun-reactive skin types I through VI. Arch Dermatol I988, I24(6):869-7I.

14. Ramsay HM, Fryer AA, Reece S, Smith AG, Harden PN: Clinical risk factors associated with nonmelanoma skin cancer in renal transplant recipients. Am J Kidney Dis 2000, 36:167-I76.

15. Luscombe CJ, Fryer AA, French ME, Liu S, Saxby MF, Jones PW, Strange RC: Exposure to ultraviolet radiation: association with susceptibility and age at presentation with prostate cancer. Lancet 200I, 358:64I-642.

16. Lovatt TJ, Lear JT, Bastrilles J, Wong C, Griffiths CE, Ramachandran S, Smith AG, Salim A, Fryer AA, Jones PW, Strange RC: Associations between UVR exposure and basal cell carcinoma site and histology. Cancer Lett 2004, 216:191-197.

17. Lovatt TJ, Lear JT, Bastrilles J, Wong C, Griffiths CE, Samarasinghe V, Roebuck J, Ramachandran S, Smith AG, Jones PW, Fryer AA, Strange RC: Associations between ultraviolet radiation, basal cell carcinoma site and histology, host characteristics, and rate of development of further tumors. J Am Acad Dermatol 2005, 52:468-473.

18. Ruppert JM, Vogelstein B, Kinzler KW: The zinc finger protein GLI transforms primary cells in cooperation with adenovirus EIA. Mol Cell Biol I99I, II:I724-1728.

19. Weir BS: Genetic Data Analysis II: methods for discrete population genetic data Sunderland MA: Sinauer; 1996.

Publish with Bio Med Central and every scientist can read your work free of charge

"BioMed Central will be the most significant development for disseminating the results of biomedical research in our lifetime. "

Sir Paul Nurse, Cancer Research UK

Your research papers will be:

- available free of charge to the entire biomedical community

- peer reviewed and published immediately upon acceptance

- cited in PubMed and archived on PubMed Central

- yours - you keep the copyright 